\title{
¿Cómo leer un film? La formación ética a través del cine y la virtualidad
}

\section{Como ler um filme? A formação ética através do cinema e da virtualidade}

Juan Jorge Michel Fariña Alejandra Tomas Maier

\begin{abstract}
Resumen: ¿Puede el cine verdaderamente ayudarnos a conocernos más y a convivir mejor con nuestro deseo? Esta pregunta se presenta tanto ante aquellos filmes en los que el director se propone de manera explícita presentar el debate moral contemporáneo, como en aquellos otros en los que son los espectadores y analistas quienes recortan en la obra de arte la ocasión para la reflexión ética. En ambos casos el resultado es una extraordinaria experiencia de pensamiento y acción. Pero persiste la pregunta: ¿Cuáles son los resortes que explican semejante potencia del cine? Este artículo ensaya una respuesta proponiendo una metodología de lectura de películas basada en el pensamiento de Badiou, Zizek, Agamben y Lacan, complementada con la utilización de recursos de educación e informática y en particular las plataformas virtuales y las redes sociales.
\end{abstract}

Palavras-clave: Educación ética. Filme. Tecnologia virtual.

Resumo: O cinema pode realmente nos ajudar a saber mais e a viver melhor com o nosso desejo? Esta questão se coloca tanto diante daqueles filmes em que o diretor propõe explicitamente apresentar o debate moral contemporâneo, como naqueles onde são os espectadores e analistas que veem na obra de arte uma oportunidade para a reflexão ética. Em ambos os casos, o resultado é uma experiência extraordinária de pensamento e ação. Mas a questão permanece: Quais são as fontes que explicam tal poder do cinema? Este artigo tenta dar uma resposta propondo uma metodologia para a leitura de filmes baseados no pensamento de Badiou, Zizek, Agamben e Lacan, complementado pelo uso de recursos de educação e informática e, particularmente, em plataformas virtuais e redes sociais.

Palavras-chave: Educação ética. Cinema. Tecnologia virtual.

\section{El animal que va al cine}

O homem é o único animal que se interessa às imagens enquanto tais. Os animais interessam-se bastante pelas imagens, mas na medida em que são enganados por elas. Podemos mostrar a um peixe a imagem de uma fêmea, ele irá ejectar o seu esperma; ou mostrar a um pássaro a imagem de outro pássaro para o capturar, e ele será enganado. Mas quando o animal se dá con-

MICHEL FARIÑA, Juan Jorge; TOMAS MAIER, Alejandra. ¿Cómo leer un film? La formación ética a través del cine y la virtualidade.Informática na Educação: teoria e prática, Porto Alegre, v. 19 n. 1, p. 69-83, jan./maio 2016. 
ta que se trata de uma imagem, desinteressa-se totalmente. Ora, o homem é um animal que se interessa pelas imagens uma vez que as tenha reconhecido enquanto tais. É por isso que se interessa pela pintura e vai ao cinema. Uma definição do homem, do nosso ponto de vista específico, poderia ser que o homem é o animal que vai ao cinema. (AGAMBEN,1998, p.65)

Desde sus inicios mismos, el cine ha desplegado las grandes problemáticas psicológicas y éticas de la existencia humana. De allí que pensadores de la talla de Jorge Luis Borges, Gilles Deleuze, Jacques Lacan, Alain Badiou, Slavoj Zizek, Italo Calvino y Giorgio Agamben, entre otros, se hayan ocupado de su potencia de pensamiento.

Existen actualmente múltiples programas, dentro y fuera del ámbito académico, que se valen de filmes para investigar temas complejos de la práctica psicológica, para ilustrar capítulos conceptuales, o para tratar el padecimiento humano.

Ya sea cuando el cine se propone de manera explícita llevar a la pantalla el debate moral contemporáneo, o cuando espectadores y analistas recortan en la obra de arte la ocasión para la reflexión ético-psicológica, el resultado es una extraordinaria experiencia de pensamiento y acción. Pero persiste la pregunta: ¿Cuáles son los resortes que explican esta potencia? Y sobre todo ¿Puede el cine verdaderamente ayudarnos a conocernos más y a convivir mejor con nuestro deseo?

Partiremos de una pregunta inesperada: ¿cuál es la manifestación estética más antigua que ha conocido la humanidad? Según el escritor argentino Jorge Luis Borges (1980, s/p), sin duda "[...] los sueños, en los cuales somos el escenario, los actores y la fábula argumental [...]". Y la más reciente, se dice, el cine, que ocupa el séptimo lugar, después de la pintura, la escultura, la poesía, la música, la danza y la arquitectura.

Así, la más novedosa y fascinante de las bellas artes se emparenta con la primera, con la originaria, con aquella que excede toda clasificación. Y ambas - es lo que se propone demostrar esta tesis -, tienen en la subjetividad que nos legó el teatro griego su inesperado punto de encuentro, su antecedente y a la vez su momento de mayor lucidez.

Esta metodología, que parte de este parentesco estructural entre el cine y los sueños, propone entregarse a la experiencia de un film y extraer de él la enseñanza sobre la existencia humana. En lugar de aplicar los conocimientos psicológicos al cine, permitir que la película haga acontecimiento en nosotros, delineando así la filigrana de nuestra concepción ético-psicológica ${ }^{1}$.

Una segunda referencia: El Big Bang del lenguaje en la causación del sujeto, título de la tesis sostenida por Alfredo Eidelsztein. En ella se fundamenta que el lenguaje humano no fue efecto de una evolución paulatina a partir del sistema de comunicación animal, sino que supuso un punto de fractura - de allí la analogía con la explosión que dio origen al universo. La referencia permite

\footnotetext{
${ }^{1}$ Este trabajo da cuenta de la experiencia en el marco de la investigación del Programa de Ciencia y Técnica de la Universidad de Buenos Aires para el período 2014-2017, "(Bio) Ética narrativa y Derechos Humanos: cuestiones ético-analíticas. En este marco y a lo largo de lo últimos veinte años se han dictado cursos para aproximadamente 40.000 estudiantes de Medicina, Derecho, Psicología, Biología y otras ramas de las ciencias básicas y aplicadas. Se han publicado cinco volúmenes sobre ética y cine (MICHEL FARIÑA; GUTIÉRREZ, 1999, LUDUEÑA; MICHEL FARIÑA, 2009, MONTESANO; MICHEL FARIÑA, 2011, MICHEL FARIÑA; SOLBAKK, 2012, BENYAKAR; MICHEL FARIÑA, 2014 y desarrollado distintos materiales multimedia en el marco del Proyecto International Bioethical Information System (IBIS). Se han creado dos sitios web de libre acceso ampliamente consultados: <www.eticaycine.org> y <www. teachingbioethics.org >además de una revista indexada y tres comunidades virtuales, dos de ellas en entorno Ning y la otra bajo plataforma Moodle. Esta tesis da cuenta de esa experiencia, a la vez metodológica y conceptual, en la que el cine aparece como una herramienta privilegiada en la transmisión del pensamiento ético contemporáneo.
} 
introducir un trabajo reciente de Ana Cecilia González, que recupera el valor analítico de los descubrimientos de Chauvet, y especialmente la resignificación que de ellos ofrece la magia del cine:

La cueva de los sueños olvidados (2010)de Werner Herzog nos introduce en la cueva de Chauvet - la "galería natural de arte" más antigua ${ }^{2}$ conocida - y hace desfilar ante nuestros ojos las maravillas del arte rupestre: bisontes, osos cavernarios, toros, mamuts, caballos, leones, una pantera, una mariposa, y una única representación del cuerpo humano, pintados con una destreza y sensibilidad apabullantes. En suma, más de 400 pinturas de unos 35.000 años de antigüedad. Descubierta en Francia en 1994 e inaccesible a los ojos del público hasta este film, la cueva es una perfecta "cápsula de tiempo", sellada hace 20.000 años, cuando una pared del acantilado se desprendió cerrando la entrada. Ingresar en ella identificados con la mirada y el relato de Herzog, es casi como volver a descubrirla y experimentar la misma extrañeza contenida en el gesto figurativo de los autores de las pinturas paleolíticas. Dicho en otros términos: entrar en la cueva supone volver a re-presentarse el vacío que lo simbólico cava en lo real. (GONZÁLEZ, 2014, s/p.)

¿Cuál es el punto en común de ambas fuentes y en qué aportan a la cuestión del cine como dimensión ética? Un detalle de las pinturas, muestra que los artistas se propusieron plasmar el movimiento, recurriendo a técnicas de animación, semejando una serie de fotogramas:

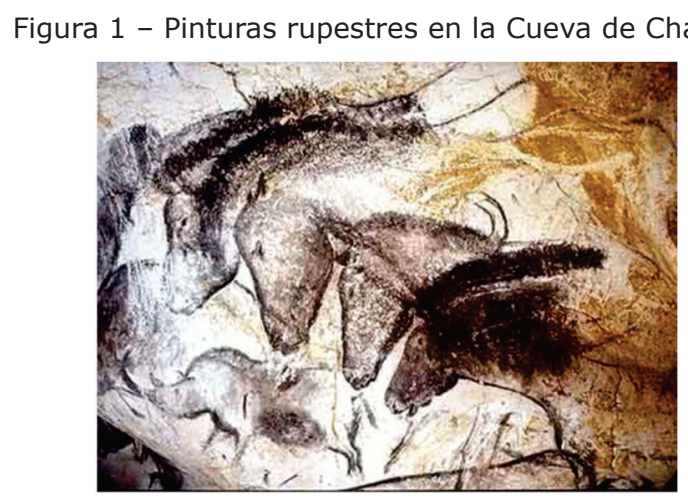

Fuente: Grotte de Chauvet

González (2014) recupera especialmente esta relación entre el arte rupestre y los rituales compartidos. Hoy se sabe que la cueva de Chauvet no estaba habitada, sino que era utilizada con fines ceremoniales. Recordamos entonces Cocinar hizo al hombre, la obra de Faustino Cordón Bonet (1980) que postula una relación entre el acto de cocinar y el advenimiento de la palabra, la cual posibilita, en la evolución de las especies, el progreso de la actividad animal desde el apremio del

\footnotetext{
${ }^{2}$ Las pinturas son más antiguas que las de Altamira (que se estiman de unos 22.340 años) y también que las de Lascaux (de uno 15.000 años). La pintura rupestre ha inspirado profusos comentarios y reflexiones filosóficas. Merece mencionarse el trabajo de Geroge Bataille (2003).
} 
hambre a la organización de una mediación. La palabra confiere así la facultad de organizar, para sí y para los demás, acciones más complejas que hoy podemos calificar como simbólicas. Siguiendo a Levi Strauss (1964)en Lo crudo y lo cocido sabemos que existe una profunda relación entre el acto de cocinar y el ritual de compartir la comida, y a su vez entre este último y la adquisición del lenguaje. Se sabe también que en el inicio de la alimentación en el período paleolítico los fogones eran comunes, lo que habla tanto de la acción de comer en grupo como de la reciprocidad, especialmente de la carne fruto de la caza (CORDÓN BONET, 1980, ROSSI, 2013). Los restos de fogones encontrados en Chauvet y la visión compartida del espectáculo de las pinturas a la luz de las fogatas, permiten la siguiente analogía, siempre siguiendo el análisis de González:

De hecho, el documental está construido para mostrar que si bien contamos con recursos tecnológicos más sofisticados, seguimos capturados en el régimen representativo, de modo que Herzog no puede sino enseñarnos las pinturas cavernarias, una y otra vez. De acuerdo con esta tesis, ingresar en la sala del cine resulta equivalente a ingresar en la cueva - lo cual se ve reforzado por el uso de tecnología 3D - y la analogía entre las pinturas y el cine es sostenida de modo explícito. Las primeras tomas dentro de la cueva, filmadas con una cámara de mano, muestran el primer plano de un bisonte pintado con ocho piernas para figurar movimiento, como los cuadros de una película animada, y la voz en off - que es la del propio Herzog - señala que esta imagen es 'casi una forma de protocine'. (GONZÁLEZ, 2014, p. 24)

Cuando Agamben (1998, p. 65) sugiere que "[...] el hombre es el animal que va al cine [...]", recuperando el valor de las imágenes en la constitución simbólica de la especie, anticipa uno de los sentidos más fuertes de la presente tesis. ¿Podemos conjeturar al hombre del paleolítico abriéndose paso con una antorcha en la oscuridad de la caverna para apreciar en sus muros la representación animada de la vida? Desde Chauvet hasta hoy, se trata de ingresar, también nosotros, al núcleo existencial de la condición humana a través de un viaje por la luz en medio de una sala oscura.

\section{3 ¿Cómo leer un film?}

\subsection{Lou Andrea Salomé y su doble hipótesis ético-analítica sobre el cine}

La relación del cine con la ética y la psicología tiene una historia que se remonta a los orígenes mismos del cine, el cual como se sabe nació en 1895, el mismo año que el psicoanálisis. Efectivamente, en 1895 Freud y Breuer publican Estudios sobre la histeria, la primera presentación de la terapia psicoanalítica, y ese mismo año en París, un 28 de diciembre, los hermanos Lumière exhiben por primera vez su invento al público: el cinematógrafo (ZIMMERMAN, 2000, LASO, 2008, TRESZEZANSKY, 2014 ).

Apenas una década después de este nacimiento simultáneo, se sitúan dos viñetas clave. La primera, con el signo de un desencuentro. Fue en 1909, cuando Freud asiste por primera vez a un 
cinematógrafo en New York y las crónicas de época indican que no se mostró en absoluto interesado en el espectáculo. La segunda, bajo el signo opuesto: el de un encuentro promisorio, a partir de una perla en la que vale la pena detenerse. El sábado 22 de febrero de 1913, Lou Andreas-Salomé y Víctor Tausk fueron juntos al cine. A la salida, Andreas-Salomé dejó testimonio de su experiencia con un texto breve que constituye un verdadero hallazgo:

¿Cómo es posible que el cine no suponga lo más mínimo para nosotros, los psicoanalistas?; no es ésta la primera vez que me lo pregunto. A los muchos argumentos que podríamos esgrimir en favor de esta cenicienta de la concepción estética del arte, corresponde añadir también un par de consideraciones puramente psicológicas. Una hace referencia a que la técnica cinematográfica es la única que permite una tal rapidez en la sucesión de las imágenes que se corresponde más o menos a nuestras propias facultades de representación, imitando en parte su carácter caprichoso. Una parte del cansancio que nos invade en las representaciones teatrales no proviene del noble afán que exige la contemplación artística, sino del esfuerzo de adaptación impuesto por la pesadez del movimiento aparente de la vida en la escena; en el cine, sin un esfuerzo semejante, se libera gran parte de nuestra atención permitiéndonos que nos rindamos más espontáneamente a la ilusión.

La segunda consideración concierne al hecho de que, aunque se puede hablar de una simple satisfacción superficial, ésta obsequia a nuestros sentidos con una profusión de formas, imágenes e impresiones de modo totalmente particular $y$, tanto para el trabajador enmudecido por la estrechez de su vida cotidiana, como para el intelectual aferrado al trajín de su profesión o de su pensamiento, significa ya de por sí un rastro de vivencia artística de las cosas. Ambos argumentos obligan, por lo tanto, a una reflexión sobre lo que el futuro del cine puede llegar a significar para nuestra constitución psíquica, la pequeña zapatilla dorada de la cenicienta de las artes. (ANDREAS-SALOMÉ, 1977)

El pasaje está extraído del diario de Lou Andreas-Salomé y anticipa dos núcleos teóricos que vertebran esta tesis. El primero, el carácter intrínsecamente movilizador de las imágenes proyectadas en la pantalla, en que se apoyan las nociones de imagen-movimiento e imagen-tiempo, conceptualizadas décadas después por Gilles Deleuze. El segundo, el valor de la experiencia cinematográfica como modeladora del carácter, ofreciendo la oportunidad de sustraer al sujeto de la pobreza moral, prodigándolo con un halo de vivencia artística, tema desarrollado casi un siglo después por Alain Badiou en sus ensayos sobre cine y filosofía.

¿Cuál es según esta doble hipótesis la ventaja que encierra el cine a la hora de transmitir situaciones dilemáticas en el campo de la ética, en relación, por ejemplo, con la argumentación filosófica o incluso con las demás artes? Tal ventaja no se encuentra en el evidente alcance masivo que posee el cine como arte y entretenimiento, ya que es esa masividad la que requiere a su vez ser interrogada: ¿cómo puede el cine alcanzar semejante popularidad?

Hay algo en la naturaleza misma del cine que le facilita su éxito sobre las demás artes: se trata de la eficacia inmediata de la visión de la imagen en movimiento. Este fenómeno no está presente en la imagen evocada - por ejemplo, en la literatura, la pintura o el teatro -. Tal como fue sugerido más 
arriba por la tesis de Lou Andreas-Salomé (1977), si bien las demás artes logran hacernos evocar realidades ausentes, éstas no alcanzan a hacernos olvidar la realidad en que nos encontramos. El cine tiene, a este respecto, la ventaja de una eficacia mayor e inmediata: logra de manera instantánea que nos sumerjamos en la realidad alternativa de la escena cinematográfica, no importa si incluso hemos llegado en mitad de la proyección de una película.

La llamada magia del cine consiste en ser un arte que plasma una realidad en el campo de la imagen de modo directo e inmediato, sin que al mismo tiempo se confunda con la realidad del espectador. Ofrece una realidad alternativa y semejante a la del espectador, pero puesta a distancia. El espectador puede así identificarse con los personajes y situaciones que le ofrece la escena fílmica, sin perder la distancia con aquello que se le muestra. Siempre siguiendo a Andreas-Salomé (1977), el cine permite al espectador evadirse, suspender temporariamente la realidad inmediata, para viajar a otra realidad - tal vez mejor, tal vez peor, pero seguramente outra - y vivir sin riesgos las pasiones, dramas, alegrías o terrores. Amamos, sufrimos, morimos o sobrevivimos, triunfamos o fracasamos. Somos llevados a otros tiempos y lugares, reales o ficticios. Somos héroes o antihéroes que enfrentan situaciones reconocibles o improbables. La ilusión del cine permite por un rato el goce imaginario de vivir otras vidas, sin los riesgos que implica encarnarlas en la realidad. Gozamos así de situaciones que en la realidad nos resultarían insoportables. Pero un buen film es además aquel que se vale de sus especiales recursos para hacernos experimentar situaciones, con el objeto de introducirnos en un problema y llevarnos a considerarlo, vale decir, a pensarlo (LASO, 2008).

\subsection{El paradigma indiciario de Carlo Guinzburg}

Fue Carlo Guinzburg (2008) quien a partir de distintas fuentes desarrolló un paradigma que puede ser considerado para nuestro campo. Tal paradigma se origina en el siglo XIX, siendo su referencia inicial la obra de Giovanni Morelli, mencionada por Sigmund Freud en el Moisés de Miguel Angel:

Mucho antes de que pudiera yo haber oído hablar de psicoanálisis vine a enterarme de que un experto en arte, el ruso Iván Lermolieff, cuyos primeros ensayos se publicaron el alemán entre 1874 y 1876, había provocado una revolución en las pinacotecas de Europa, volviendo a poner en discusión la atribución de muchos cuadros a los diferentes pintores, enseñando a distinguir con seguridad entre imitaciones y originales, y edificando nuevas individualidades artísticas a partir de las obras que habían sido libradas de anteriores atribuciones. Habían alcanzado ese resultado prescindiendo de la impresión general y de los rasgos fundamentales de la obra, subrayando en cambio la característica importancia de los detalles secundarios, de las peculiaridades insignificantes, como la conformación de las uñas, de los lóbulos auriculares, de la aureola de los santos y otros elementos que por lo común pasan inadvertidos, y que el copista no se cuida de imitar, en tanto que cada artista los realiza de una manera que le es propia. Más tarde, fue muy interesante para mí enterarme de que tras el seudónimo ruso se escondía un médico italiano apellidado Morelli. Nombrado senador del reino de Italia, Morelli murió en 1891. Yo creo que su método se halla estrechamente emparentado con la téc- 
nica del psicoanálisis médico. También ésta es capaz de penetrar cosas secretas y ocultas a base de elementos poco apreciados o inadvertidos, de detritos o 'desperdicios' de nuestra observación. (FREUD, 1914)

Tal como lo consigna Freud, Morelli desestima los elementos más evidentes y se detiene en detalles y pequeñeces (los lóbulos de las orejas, la forma de los dedos, las uñas, etc.), pormenores de la obra unánimemente desatendidos por la crítica convencional. Según Guinzburg (2008), este procedimiento es análogo al que siguen Conan Doyle (a través de su personaje Sherlock Holmes) y el propio Sigmund Freud. Estos autores se detienen en aquellos indicios que escapan a la observación genérica. "En los tres casos, se trata de vestigios, tal vez infinitesimales, que permiten captar una realidad más profunda, de otro modo inaferrable. Vestigios, es decir, con más precisión, síntomas (en el caso de Freud), indicios (en caso de Sherlock Holmes) rasgos pictóricos (en el caso de Morelli)" (GUINZBURG, 2008, p. 143). Esa tarea de pesquisa, indagación pormenorizada, detección de datos marginales y privilegio de los detalles poco perceptibles configuran lo que Guinzbug Ilama "paradigma indiciario" y que contrapone al modelo galileano. Comparando esta vía con la del antiguo cazador Guinzburg dice:

Lo que caracteriza a este tipo de saber es su capacidad de remontarse desde datos experimentales aparentemente secundarios a una realidad compleja, no experimentada en forma directa. Podemos agregar que tales datos son dispuestos siempre por el observador de manera que da lugar a una secuencia narrativa. (GUINZBURG, 2008, p. 144)

Los términos elegidos por el autor son de enorme relevancia. Hay datos experimentales, pero esos datos están dispuestos por el observador y con ellos construye una secuencia narrativa. De algún modo, el observador realiza una construcción que no estaba dispuesta previamente sino que se produce -conjeturalmente- en la interpretación de esos datos.

\subsection{El razonamiento abductivo de Charles Peirce}

Existe la posibilidad de establecer un lazo entre el paradigma indiciario y los desarrollos de Peirce situando así la importancia que esta perspectiva podría tener para la relación entre cine y psicoanálisis ${ }^{3}$. El planteo de Peirce implica un salto epistemológico al agregar, a los métodos establecidos de deducción e inducción, el método de abducción que consiste en una operación semiótica sostenida en tres términos que configuran un triángulo: objeto, representamen e intérprete. El acto semiótico se produce sobre la base de esos tres términos: "Por semiosis entiendo una acción, una influencia que sea, o involucre, una operación de tres elementos, como por ejemplo un signo, su objeto y su interpretante, una relación tri-relativa, que en ningún caso se puede resolver en una acción entre dos elementos" (PEIRCE, 1998, citado por PULICE, G. et al, 2007 p. 131).

\footnotetext{
${ }^{3}$ La mención a Sherlock Holmes y el método abductivo de Peirce fueron desarrollados por Gabriel Pulice (2012); ver en esta misma línea la obra de Mariana Gómez (2007).
} 
Como es evidente, es la operación semiótica puesta en marcha por el intérprete la que permite ese lazo de los términos que, conviene insistir, nunca tiene existencia entre dos de sus términos (cualesquiera sean). Es por ello que la figura del triángulo no es la más adecuada: cada vector del triángulo conecta dos términos prescindiendo de los otros vectores. Fue por ello que Lacan, siguiendo a Peirce (1998 citado por PULICE, G. et al, 2007 p. 131), propuso su célebre noción de nudo borromeo: figura de los tres anillos que se encuentran reunidos sólo por la presencia de los tres términos. Cualquiera de los anillos que desapareciera desarma el lazo.

\subsection{La conjetura clínico-analítica: Jacques Lacan, Slavoj Zizek, Alain Badiou}

En su conocido ensayo sobre cine y filosofía, Alain Badiou señala una diferencia crucial entre el cine y el resto de las artes. Mientras que éstas buscan la pureza en el acto creador - como la pintura - la escritura, que arrancan de la hoja o el lienzo en blanco y desde allí edifican la perfección de su obra -, el cine opera exactamente a la inversa. Al inicio de una realización cinematográfica, hay demasiadas cosas. Infinitos guiones, muchísimos actores, múltiples escenografías... y la tarea del artista radica en descartar, para deshacerse de una parte del material e ir conformando su obra con lo que va quedando, con lo que emerge de ese proceso - de allí que Badiou (2004, p. 33) compare a la creación cinematográfica con el tratamiento de la basura. También es esa la razón por la que en cualquier película, aun en las que podemos considerar obras de arte, persistan elementos prescindibles - actores secundarios deplorables, música sensiblera, pornografía de más, etc. Para concluir, es el espectador en la sala de cine quien termina de construir la obra al operar algo de esta transformación, de esta depuración, durante la exhibición misma del film. En términos de Alain Badiou,

[...] la relación con el cine no es una relación de contemplación. [...] En el cine tenemos el cuerpo a cuerpo, tenemos la batalla, tenemos lo impuro y, por lo tanto, no estamos en la contemplación. Estamos necesariamente en la participación, participamos en ese combate, juzgamos las victorias, juzgamos las derrotas y participamos en la creación de algunos momentos de pureza. (BADIOU, 2004, p. 71)

Si es el espectador quien libra esa batalla en la que participa del acto creador, una buena película será entonces aquella en la que hay muchas derrotas, pero algunas grandes victorias.

$Y$ allí radica la diferencia entre el crítico de cine y el analista que toma su enseñanza de la experiencia del cine. Donde el primero ve una escena mal filmada, el segundo puede leer la magia de un significante. Significante que retroactivamente permite edificar un imprevisto giro que nos reconcilia con el film, no como operación racional, consciente, sino como un efecto que se produce en el cuerpo del espectador. No estamos buscando la pureza, y por lo mismo podemos encontramos con ella, allí donde el error se nos revela como virtud, y el paso en falso como imprevista vacilación calculada, en este caso de un realizador de cine.

Hay una expresión en música que dice así: una sola nota falsa echa a perder una fuga, pero una nota justa, a tiempo, salva una sinfonía. La fuga, recordémoslo, es la forma musical que inmortalizó Bach y que se caracteriza por una concepción perfecta de contrapuntos temáticos, orga- 
nizados de acuerdo a un sistema lógico-matemático. De allí que baste una nota falsa para echar a perder toda la ejecución. En la fuga estamos presos de necesidad. La sinfonía, en cambio, puede tener momentos difíciles, aciagos, pero siempre es capaz de rescatarse a sí misma si acontece una victoria - un oboe magistral, un solo de clarinete limpio e inspirado. En la sinfonía puede hacer su entrada el azar, a condición de que artista y espectador pueden permitirse hacer algo con él4.

En síntesis, esto que llamamos la lectura ético-clínica de un film resulta un recurso metodológico que funda nuestro escenario de trabajo, a la vez que lo trasciende. Se trata de un abordaje que no da como supuesto el dato a investigar, sino que lo conjetura a partir de indicios, detalles que a posteriori permitirán (de) mostrarlo.

\subsection{Jacques Lacan: ¿Qué es un acto? Lo imposible sucede}

Este punto de encuentro entre los hechos y la mirada analítica, reconoce por cierto distintas fuentes epistemológicas, a la vez que se distingue de ellas. ¿Qué aporta entonces Lacan al método de lectura de películas? Para el psicoanálisis, la responsabilidad se anuda dialécticamente con la culpa. Muchas veces el sujeto se culpa (y en exceso) por lo que no hizo para evitar responder por lo que sí hizo. Estamos ante una de las lecciones fundamentales del psicoanálisis lacaniano: la admisión de culpa por parte del sujeto siempre funciona como una estratagema para engañar al Otro. El sujeto se siente culpable por sus hechos para encubrir otra culpa mucho más radical. Confesarse culpable es entonces, en última instancia, una astucia que apunta a entrampar al Otro. En el film clásico Nunca en domingo, el sujeto se siente culpable por haber traicionado la buena fe de la dama, para no responder por su deseo carnal hacia ella. Por ello, avergonzarse y pedir disculpas no salda su deuda con el Otro, sino que la incrementa. Esta imposibilidad no se resuelve en el remordimiento rumiante, sino en acto.

Recordemos que la fórmula lacaniana para superar una imposibilidad no es todo es posible, sino lo imposible sucede. Lo real/imposible lacaniano no es una limitación a priori que debería ser tomada en cuenta, sino el dominio del acto, de las intervenciones que pueden cambiar las coordenadas de ese acto mismo. En otras palabras, un acto es más que una intervención en el dominio de lo posible: "[...] un acto cambia las mismísimas coordenadas de lo que es posible y así crea retroactivamente sus propias condiciones de posibilidad [...]" (ZIZEK, 2011a ou 2011b, p. 30).

En palabras de Slavoj Zizek:

[...] para Lacan, o Real não é impossível no sentido de nunca poder acontecer - um núcleo traumático que escape permanentemente a nossa apreensão. Não, o problema do Real é que ele acontece, e esse é o trauma. A questão não é que o Real seja impossível, mas que o impossível é Real. Um trauma ou um ato é simplesmente o ponto em que o Real acontece, e isso é difícil de aceitar. (ZIZEK, 2004, p. 89)

\footnotetext{
${ }^{4}$ En el film El concierto (2009), dirección de Radu Mihaileanu, se narra la historia de la performance del concierto en Re Mayor para violín y orquesta de Tchaikovsky a cargo de la vieja orquesta del Bolshoi, la cual en la ficción del film hacía treinta años que no tocaba. Los músicos llegan a la noche del debut en el Chatelet de Paris sin ensayos previos y el inicio es decepcionante. La orquesta suena desafinada hasta el punto que el público y los propios músicos se incomodan, pero todo cambia cuando hace su entrada el violín. Singularmente inspirado esa noche, su ingreso a tiempo rescata la obra, aconteciendo una ejecución magistral e inolvidable.
} 
Lo imposible sucede es un enunciado ético situacional. Responder por aquello que falla en una situación supone responsabilizarse por ella. Pero no en las coordenadas previsibles, sino en el a posteriori de una invención. Por supuesto este movimiento estará finalmente en lo que el sujeto pueda hacer con ello.

A partir de este giro, de este cambio de luces que nos propone el psicoanálisis, cambia también nuestra perspectiva de lectura de un film. De pronto, el pueril altruismo de muchos personajes en la pantalla se explica por el virulento deseo que se agita dentro de ellos. Deseo frenético que se expresa en los pequeños detalles, como ese -iplin, caja! - que suena en el film Nunca en domingo y que le permite afirmar a Lacan (1988, p. 377): "Lo que hace que pueda haber deseo humano, que ese campo exista, es la suposición de que todo lo que sucede de real es contabilizado en algún lado". De allí que el pasaje del film merezca el valor de un apólogo, es decir de una narración cuyo propósito es instruir sobre algún principio ético o moral o de comportamiento.

\section{Informática, Educación y transmisión de la experiencia del cine}

Como se sabe, la Ética es una disciplina transversal de la educación. No estamos ante una asimilación de contenidos sino ante el desafío de una permanente interpelación y reflexión. Por tratarse de conocimientos complejos relacionados con la práctica misma de los profesionales, se busca justamente apelar a metodologías que puedan poner en situación al auditorio.

La corriente narrativa, al ofrecer el espacio y la distancia suficiente para que dicha experiencia pueda ser instrumentada con la disociación necesaria, evita constituir en sí misma una conmoción disruptiva. Al mismo tiempo, la narrativa ofrece la afectividad y receptividad suficientes para estimular la sensibilidad, apuntando a conmover su posición, logrando una empatía con los sentimientos, sensaciones, valores y creencias en juego.

De allí la importancia del cine: un dispositivo que espontáneamente establece una dimensión del pathos, de los sentimientos, las emociones, las pasiones, permitiendo establecer una relación con los objetos teóricos.

Dicha modalidad resulta esencial a la hora de transmitir, logrando estimular una empatía con los actores sociales involucrados en las situaciones dilemáticas de la práctica, favoreciendo el desarrollo de un pensamiento crítico, y promoviendo una actitud ética en la resolución de conflictos.

\subsection{Las plataformas virtuales como soporte privilegiado}

El objetivo esperable es que el acercamiento a los dilemas éticos presentados de forma mediada, sumados a la capacitación y acompañamiento de los futuros profesionales en su formación académica, permita la inclusión de estas temáticas de forma mucho más vivencial. En este punto, las TICs permiten una implementación dinámica y eficaz de los recursos audiovisuales y posibilita una interacción absolutamente novedosa.

Es en este sentido que se considera a los recursos audiovisuales como dispositivos didácticos por excelencia, en tanto permiten recrear una situación, en un lapso acotado de tiempo, mediante 
la proyección de fragmentos.

Para ello, el uso de los recursos tecnológicos que ofrecen plataformas virtuales como Moodle y Ning permite potenciar este proceso de enseñanza y aprendizaje ya que ofrece herramientas valiosas para su implementación y, principalmente, el desarrollo del trabajo colaborativo entre los miembros de la comunidad virtual, complementando así el trabajo realizado en las instancias presenciales, y alentando en acto el ámbito deliberativo.

\subsubsection{Moodle y Ning: Teaching Bioethics Through Films}

El proyecto al que hacemos referencia se desarrolla en el marco general del proyecto UBATIC: Aula Virtual, módulo intercátedras de ética, ciencia y tecnología 5 El curso se propone impartir conocimientos sobre Ética contemporánea a través de una experiencia teórica y narrativo-audiovisual: cine, teatro, series televisivas. Las unidades del programa temático han sido confeccionadas a partir la Declaración Universal de Bioética y Derechos Humanos (UNESCO, 2005).

En este contexto la plataforma Moodle y los recursos que la misma ofrece permite potenciar el uso de los materiales multimedia, optimizando la comprensión de los contenidos a desarrollar en el curso. La propuesta se desagrega en dos partes:

- Impartir un módulo de Ética y Ciencia del programa de la asignatura para los estudiantes de grado.

- Impartir conocimientos generales sobre Bioética para estudiantes de posgrado y graduados de ciencias básicas y de la Salud.

En el primer caso, el curso se propone un recorrido por el módulo de Ética y Ciencia: Módulo 6 del curso Moodle (Consentimiento), mediante los recursos audiovisuales propuestos que también integran el material obligatorio del programa de cátedra, con la adición de realización de trabajos prácticos, resolución de consignas y discusiones. Ello permitirá al alumno un mayor manejo de las nociones centrales de dicho módulo que le permitirán en caso de aprobación del curso, dar cuenta de los requisitos necesarios para la aprobación de la materia.

En el segundo caso, permite un manejo fluido de los principios contenidos en los 15 artículos centrales de la Declaración Universal de Bioética y Derechos Humanos (UNESCO, 2005) a partir de una experiencia audiovisual sostenida en la corriente narrativa de la Bioética contemporánea.

\subsubsection{El cine y la tecnología computacional}

La propuesta implica la inserción de materiales audiovisuales pertinentes en cada una de las unidades recorridas, a fin de realizar actividades previa y posteriormente al visionado de tales fragmentos cinematográficos. Para los encuentros presenciales programados se realizarán proyecciones procurando un formato mínimo que garantice la experiencia vivencial esperada.

La presentación involucra un desarrollo que acompañe, en sentido amplio, el material audio-

\footnotetext{
${ }_{5}^{5}$ Programación 2012-2015: Ética y ciencia: Programa de base de estudios sobre bioética, desarrollado y ejecutado por el equipo de la Cátedra de Psicología, Ética y Derechos Humanos de la Facultad de Psicología de la Universidad de Buenos Aires.
} 
visual. Es decir, que formule en términos teóricos el recorrido que se pretende realizar audiovisualmente, así como la fundamentación de la pertinencia del mismo, que luego se abordará asimismo en la plataforma de trabajo Moodle. Para ello, se llevan a cabo dichas presentaciones, seguidas de breves espacios de intercambio respecto a los contenidos, las emociones y las impresiones detectadas, para luego dar lugar a formalizar el material obtenido dentro del encuadre trabajado.

En los casos en los que los contenidos del curso se desarrollan únicamente en la modalidad virtual, esto se ve alentado por medio de espacios compartidos, como foros y discusiones abiertas sólo a los matriculados bajo dicha modalidad. La actividad es así sostenida y moderada del mismo modo por los docentes ocupados de las modalidades presenciales y/o los ayudantes, bajo su supervisión.

\section{Epílogo y conclusión}

Sin aspirar a ese lugar imposible de Gesamtkunstwerk, de obra de arte total, el cine constituye sin embargo una vía regia para pensar los distintos dilemas éticos. Con el crecimiento y expansión de la industria cinematográficas, los grandes temas morales fueron alcanzando a un público cada vez más masivo, promoviendo interesantes debates dentro y fuera de los ámbitos académicos. Hoy la experiencia del cine forma parte de la vida cotidiana gracias a la tecnología digital y al visionado de filmes y fragmentos on line, lo cual ha facilitado, además, su uso en programas de formación a distancia.

El cine adquiere así la función que antaño correspondió al teatro griego. La experiencia de la luz en medio de una sala oscura recupera algo de la experiencia trágica, que como lo estableció Aristóteles consistía en la mímesis de una praxis para producir en el auditorio un efecto de catarsis. Gran parte de la literatura disponible se apoya en la mirada analítica, inspirada en el pensamiento de Sigmund Freud, quien anticipó la naturaleza compleja de la noción de cuerpo, y de Jacques Lacan, inesperado precursor de la bioética narrativa al constatar que la verdad tiene estructura de ficción (GÓMEZ, 2007).

Para concluir, recordemos entonces el axioma según el cual el artista se adelanta al analista, evocando los versos del poeta:

\section{Cinema}

Na grande sala escura, só teus olhos existem para os meus: olhos cor de romance e de aventura, longos como um adeus.

Só teus olhos: nenhuma atitude, nenhum traço, nenhum gesto persiste sob o vácuo de uma grande sombra comum. 


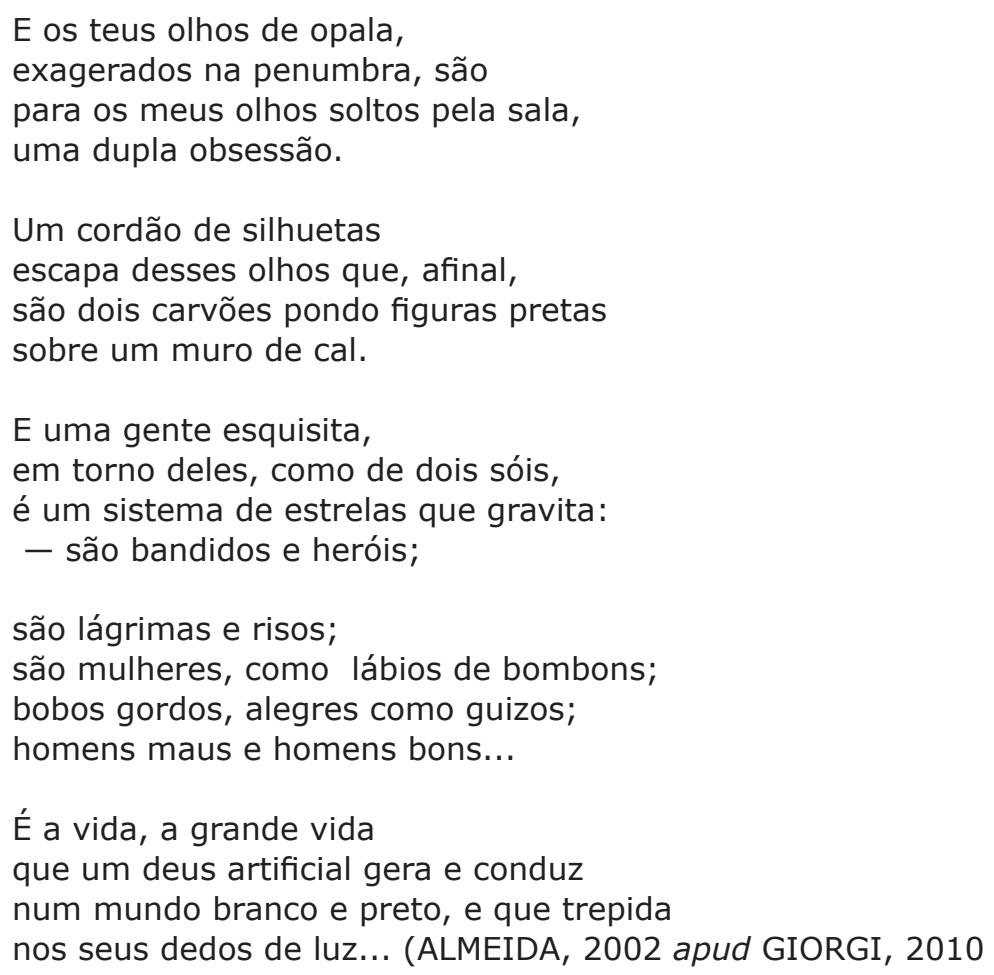

\section{Referencias}

AGAMBEN, G. Le cinéma de Guy Debord. In: AGAMBEN, G. Image et mémoire. Genève: Éd.Hoëbeke, 1998. P. 65-76.

ANDREAS-SALOMÉ, L. La pequeña zapatilla dorada. In: ANDREAS-SALOMÉ, L. et al. Aprendiendo con Freud: diário de un año 1912-1913. Barcelona: Laertes, 1977. P. 101-102.

BADIOU, A. El cine como experimentación filosófica. In: YOEL, G. Pensar el cine 1: imagen, ética y filosofía. Buenos Aires: Manantial, 2004.

BATAILlE, G. Lascaux o el nacimiento del arte. Córdoba: Alción Ed., 2003.

BONET, F. C. Cocinar hizo al hombre, Barcelona : Tusquets Ed., 1980.

BORGES, J.L. Siete noches. Buenos Aires: Emecé, 1980.

FREUD, S. El "Moisés" de Miguel Angel. Imago, v. 3, n. 1, p. 15-36, 1914. 
GINZBURG, C. Indicios: raíces de un paradigma de inferencias indiciales. In: GINZBURG, C. Mitos, emblemas, indícios: morfología e historia. Barcelona: Gedisa, 2008. P. 138-175.

GIORGI, A. de V. Cinema com Nancy. Anuário de Literatura, v. 15, n. 1, p. 282, 2010.

GÓMEZ, M. Del significante a la letra: La semiótica peirceana en el proceso de formulación del discurso lacaniano. Córdoba: Alción Ed., 2007.

GONZÁLEZ, A.C. La extimidad amenazada. Etica y Cine Journal, v. 4, n. 2, p. 23-29, 2014. Disponible en: <http://journal.eticaycine.org/IMG/pdf/JEyC_Julio_2014_Gonzalez_Extimidad.pdf>. Acceso en: 22 oct, 2015.

LACAN, J. Seminario 7: La ética del psicoanálisis (1959-1960). Buenos Aires: Ed. Paidós, 1988.

LASO, E. El cine como recurso de pensamiento en el campo de la ética. Buenos Aires, 2008. Trabajo presentado em XV Jornadas de Investigación, Cuarto Encuentro de Investigadores en Psicología del Mercosur "Problemáticas actuales. Aporte de la investigación en psicología", 2008, Facultad de Psicología, Universidad de Buenos Aires, AR.

MICHEL FARIÑA, J. J.; LUDUEÑA, F. Etica y magia a traves del cine: El acto de prestidigitacion e el acontecimiento clinico (Ethics and Magic through Movies: Act of Prestidigidation and Clinical Event). Dynamo Editorial, Buenos Aires. 978-987-25132-0-7. 126. 2009.

MICHEL fARIÑA, J.J.; GUTIÉRREZ, C. Ética y Cine. Buenos Aires: Eudeba, 1999.

MICHEL FARIÑA, J.J.; SOLBAKK, J.H. (Bio)ética y cine: Tragedia griega y acontecimiento del cuerpo. Buenos Aires: Letra Viva Ed., 2012.

MONTESANO H., MICHEL FARIÑA J. J. (Comp.) Grey's Anatomy. En Cuestiones ético-clínicas en series televisivas. Dr. House, In treatment, Los Soprano, Grey's anatomy. Buenos Aires: Dynamo Editorial. 2011.

PEIRCE, C. S.; The Essential Peirce. Vol II; The Peirce Edition Project; USA; 1998.

PULICE, G. Peirce en Lacan: Algunas herramientas semióticas para la investigación de la subjetividad. Navarra, 2012. Conferencia dictada en la Universidad de Navarra, España, el 22. oct, 2012.

PULICE, G., ZELIS, O., MANSON, F; Investigar la Subjetividad; Buenos Aires; Letra Viva 2007. Capítulo 6. 
ROSSI, L. "Historia del comer. Lazo social y tradición cultural" 2013. Intersecciones, año 4, v.10. http://intersecciones.psi.uba.ar/index.php?option=com_content\&view=article\&id=195: historiad elcomerlazosocialytradicioncultural\&catid=10:vigencia\&Itemid=1 Acceso en: 10 mai 2015.

STRAUSS, L. Lo Crudo Y Lo Cocido, volumen I de Mitológicas, Paris: Plon, 1964.

TRESZEZANSKY, J. Freud de la butaca a la pantalla. En BENYAKAR, M. MICHEL FARIÑA, J. J. Lo disruptivo em El cine (comps.) Buenos Aires: Letra Viva, 2014.

UNESCO. Declaración Universal sobre Bioética y Derechos Humanos. Paris, 2005. Disponible em: <http://unesdoc.unesco.org/images/0014/001461/146180s.pdf>. Acceso en: 10 mai, 2015.

ZIMMERMAN, D. Contornos de lo real. Buenos Aires: Letra Viva, 2000.

ZIZEK, S. Cómo leer a Lacan. Buenos Aires: Paidós, 2011 a.

ZIZEK, S. Bienvenidos a tiempos interessantes. La PaZ: [s.n.], 2011b.

ZIZEK, S.; DALY, G. Arriscar o Impossível. São Paulo: Martins Fontes, 2004.

Filmes citados:

EL CONCIERTO. Direción: Radu Mihăileanu. Producción: Alain Attal. [S.I.]: BiM Distribuzione, 2009. Duración: 119min. 